\title{
Homenaje a Crescencio Ruiz Chiapetto
}

El Maestro Crescencio Ruiz Chiapetto falleció el 10 de enero de 2007 en la Ciudad de México. En una muestra de afecto, el Centro de Estudios Demográficos, Urbanos y Ambientales organizó el 24 de enero un homenaje a su memoria. A continuación se presentan las palabras de cada participante en su intervención:

\section{Palabras iniciales}

\section{José Luis Lezama}

Estamos aquí reunidos para honrar la memoria de un colega, de un amigo que ya no está más entre nosotros. Cada vez que esto ocurre queda en nosotros la sensación de que algo nos falta, que ya no estamos completos. A todos nos sorprendió y dolió la muerte de Crescencio, a quien aprendimos a apreciar en sus diversas facetas y en los distintos aspectos de su personalidad. Su ausencia es motivo de este homenaje. A través de su recuerdo nos reconocemos como un grupo del que era parte nuestro colega y amigo. Posiblemente no hubiera estado de acuerdo con que le rindiéramos este homenaje, porque tengo la impresión de que no era afecto a estos actos; no parecían gustarle mucho las solemnidades. No obstante, para nosotros Crescencio merece ser recordado por diversos motivos, entre otros por los sentimientos que nos genera su ausencia y por los que nos generó su presencia durante el tiempo que convivimos con él. No quisiera hablar de más, tan sólo pretendo expresar unas cuantas cosas que hablan de él. En lo personal lo recuerdo con especial afecto, sobre todo por el apoyo que me brindó en estos años durante los cuales he sido director del CEDUA.

Crescencio será recordado en el ámbito académico porque realizó importantes contribuciones al estudio de los fenómenos urbanos. Junto con Luis Unikel y Gustavo Garza, participó en la elaboración de la primera obra sistemática, profesional y de carácter científico sobre el proceso de urbanización en México. El libro El desarrollo urbano en México. Diagnóstico e implicaciones futuras apareció en un momento decisivo para la planeación urbana en nuestro país. Con esa obra puede decirse que se sientan las bases analíticas y conceptuales para el nacimiento de la planeación urbana en el país como una actividad racional, positiva, propositiva y con sustento científico. Fue precisamente a

ESTUDIOS DEMOGRÁFICOS Y URBANOS, VOL. 22, NÚM. 2 (65), PP. 461-475 
mediados de los setenta cuando el Estado mexicano inició el proceso más sistemático de planeación. El libro de Unikel, Garza y Ruiz Chiapetto constituyó el diagnóstico en el que se basó la planeación urbana -al menos desde el ámbito discursivo- como una parte significativa de todo el proceso de planeación del desarrollo. De este libro nació también el diseño de la maestría en Desarrollo Urbano, cuya primera generación arrancó en 1976 y en la que Crescencio participó como profesor en distintas asignaturas. Posteriormente también hizo importantes contribuciones al estudio de la urbanización, la dinámica de las ciudades y la movilidad de la población. En todos sus trabajos mostró un rigor que a veces podría parecer excesivo y un afán perfeccionista. No liberaba ningún trabajo para su publicación si no estaba convencido de que en verdad el fondo y la forma eran relevantes. Creo que se sentía mejor como investigador que como profesor. Me da la impresión que la docencia no era algo en lo que se sintiera mucho a sus anchas. No obstante, sus alumnos lo recuerdan con afecto y agradecimiento por su labor docente; hemos recibido cartas de condolencias de muchos estudiantes de México y distintos países de América Latina.

Invitamos a participar en este homenaje a un grupo de colegas y amigos que convivieron de manera especial con Crescencio, y que compartieron con él algunas de las facetas de su vida.

\section{Homenaje póstumo a Crescencio Ruiz Chiapetto}

\section{Gustavo Garza}

El proyecto de la investigación titulada El proceso de urbanización en México se efectuó bajo la coordinación de Luis Unikel en 1966 y parte de 1967, año en que Crescencio Ruiz Chiapetto se incorporó al equipo que la realizaba. En este último año había terminado la maestría en Economía y se iniciaba como investigador en una temática que al principio le era extraña.

En el proyecto se concebía al proceso de urbanización de México en forma multidimensional, esto es, que el estudio del desarrollo urbano debería superar los enfoques "urbanístico-arquitectónicos", e incorporar los factores económicos, políticos y sociales que determinan la dinámica urbana. No obstante, como punto de partida se realizó un análisis macroestadístico de la evolución del sistema de ciudades en el país y de sus características centrales, para posteriormente poder pro- 
fundizar en aspectos más específicos de ciudades o regiones individuales, así como en otras dimensiones de su relación con la estructura económica y social.

De esta suerte, se introdujeron en forma de una relación circular causa-efecto-causa algunas de las variables económicas, demográficas, ecológicas e históricas que explican la dinámica urbana de las naciones. Ésta es la razón por la que, siendo Luis Unikel ingeniero civil, contrató a Crescencio en 1967 para trabajar algunos de los aspectos económicos del proyecto.

Dos años después, en 1969, egresé igualmente de la maestría en Economía y siguiendo la trayectoria de Crescencio, empecé a laborar a partir de octubre de ese año en un tema que al principio también ignoraba absolutamente. Fue como lo conocí en mi calidad de investigador principiante, siendo él un investigador con dos años de experiencia; en ese carácter, me comentaba sobre las costumbres laborales de la institución y sobre ciertas peculiaridades idiosincrásicas de Luis Unikel. Entre 1972 y 1973 me fui un año a estudiar a Inglaterra, pero al regresar me reincorporé al proyecto. Al casarme con Brígida García en 1973 Crescencio fungió como "testigo del contrayente", y a partir de ello mantuvimos en esos años una gran amistad con él y Martha Elena, así como nuestros pequeños hijos con Marianita, su hija.

En 1972 se inició el armado de los resultados que se habían publicado del proyecto para articularlos en forma de libro. Esta parte, en palabras de Luis Unikel, "se convirtió a la postre en una nueva etapa de trabajo, no menos exenta de escollos que la investigación en sí" (p. 7). Así, todos los trabajos anteriores habían estudiado el periodo 1940-1960, por lo que se requería actualizarlos con los censos de 1970, además de que se decidió extender el análisis retrospectivo del sistema de ciudades desde 1900. Agrega Unikel que varios de los borradores fueron reelaborados por nuevos investigadores ante su permanente movilidad, de tal suerte que "al final de cuentas, la mayor parte de la elaboración del libro fue realizada por Luis Unikel, coordinador del proyecto, en colaboración con Crescencio Ruiz Chiapetto y Gustavo Garza Villarreal" (p. 7-8).

Cabe señalar a este respecto que cuando Luis Unikel estaba de sabático en Inglaterra en 1974, Víctor L. Urquidi -en ese tiempo presidente de El Colegio de México-, nos urgió a Crescencio y a mí a que termináramos el trabajo, pues planeaba presentarlo en el Premio Nacional de Economía (Banamex), y la fecha límite para registrarlo era el 31 de diciembre de 1974. No recuerdo haber visto posteriormente 
a Crescencio tan entusiasmado como cuando trabajamos juntos para culminar el libro, no obstante que en los últimos meses teníamos que laborar los siete días de la semana.

En el prólogo se indica que Crescencio Ruiz Chiapetto es autor de los capítulos VI. "Desarrollo económico regional y urbanización", y VII. "Factores determinantes de la migración rural-urbana". Es relevante señalar que estas dos temáticas (desigualdades regionales y migración interna), fueron su tema de especialización a lo largo de sus 40 años de investigador en nuestra institución; sobre ellas giran sus publicaciones posteriores a la aparición de El desarrollo urbano de México. Diagnóstico e implicaciones futuras.

En el capítulo VI sobre el "Desarrollo económico regional y urbanización”, Crescencio se plantea "averiguar si la dinámica del desarrollo económico regional en México ha tenido una asociación específica con el proceso de urbanización" (p. 176). Concretamente se trataba de ver la sincronía o asincronía entre los procesos y determinar la tendencia de las desigualdades regionales entre 1940 y 1970. Advierte que el análisis de la relación entre ambos procesos es complejo, pues no existe una teoría que explique sus vínculos. Lo que se suele hacer es una mera asociación, en forma o no de función algebraica, con un grado de explicación relativamente limitado. A 30 años de haberse escrito este planteamiento, desde mi punto de vista continúa siendo válido, pues el desarrollo de la disciplina urbano-regional ha sido más bien empírico o mediante la elaboración de modelos formales, centrales en los enfoques de corte neoclásico, pero aún muy irreales (tales como los desarrollados actualmente en la llamada "nueva geografía económica").

No es pertinente en este momento describir los hallazgos de Crescencio Ruiz Chiapetto en este capítulo, pero podemos mencionar que la dinámica de las desigualdades regionales encontrada se mantiene hasta los años noventa del siglo pasado, además de que parece retomarse ante el impacto territorial del TLC-AN, al menos hasta el colapso del modelo maquilador en el primer lustro del siglo XXI. Indefectiblemente, el capítulo continúa siendo un trabajo clásico y de los más rigurosos sobre la tendencia de las desigualdades regionales en México.

El análisis de Crescencio Ruiz Chiapetto de los determinantes de la migración rural-urbana realizado en el capítulo VII pone a prueba las concepciones en boga en esa época -que en buena medida continúan en la actualidad-sobre el interjuego de factores de expulsión del campo y de atracción en la ciudad, las condiciones físicas entre ambos sectores, las peculiaridades del emigrante y el impacto de las 
transformaciones de la estructura socioeconómica. Una cuestión innovadora en su enfoque fue la introducción del tamaño de la ciudad y la integración de subsistemas urbanos en la asociación de los factores de atracción y la migración a las ciudades. A este respecto afirma que las localidades del hinterland de la Ciudad de México-Puebla, Toluca, Cuernavaca y Querétaro- registran un acelerado crecimiento social, y pronostican que seguirán constituyendo una de las principales zonas de atracción de inmigrantes en el país. En buena medida esto ha ocurrido, pues en los ochenta se constituyó la megalópolis de la Ciudad de México y las ciudades de su subsistema siguen atrayendo población hasta la actualidad.

Otra de las conclusiones de Crescencio tuvo alguna trascendencia, aunque no la deseada, en la peculiar vida de nuestro sistema político. Salió en los periódicos su afirmación de que una mayor productividad en el sector rural originaba mayor migración, y no a la inversa, como comúnmente se pensaba. Como el gobierno de Luis Echeverría tenía un programa de modernización del campo para "frenar la migración a la ciudad”, el señor Urquidi nos mandó llamar una mañana para decirnos que el presidente de México quería tener una reunión con nosotros. Lo acompañamos a Los Pinos, donde estuvimos desde las 9:00 hasta las 20:00 horas escuchando de diferentes secretarios de Estado y altos funcionarios todos los programas regionales que estaban ejecutando. Prácticamente no hubo ninguna interlocución y después de que el presidente nos saludó protocolariamente, nos despidieron agradeciendo nuestro interés en conocer todas sus acciones de política urbana y regional. Salimos perplejos, pero el señor Urquidi nos sacó de nuestro marasmo comentando: ¡Así es el sistema político mexicano!

Me gustaría terminar con una reminiscencia sobre la costumbre que mantuvimos desde los años setenta de decirnos, como se acostumbraba en la época, "Maestro" al saludarnos; _¿Cómo estás Maestro?-, preguntábamos a guisa de saludo.

La última vez que platiqué con Crescencio fue el 14 de diciembre del año pasado, cuando nos encontramos caminando por un pasillo de El Colegio: -¿Cómo estás Maestro?-, interrogué. -Con una “tosesita" que no se me quita-, me respondió. Le señalé que seguramente se debía a las pronunciadas variaciones de la temperatura durante el día en el invierno. En su peculiar e inefable sonrisa, a la que solía agregar un comentario irónico, exclamó: -¡Que va ser! ¡Es la bola de años!-. Imposible adivinar que sería la última vez que lo vería.

Descansa en paz, Maestro. 
Crescencio Ruiz Chiapetto (1940-2007)

\section{Boris Graizbord}

El Maestro nació en San Luis Potosí en abril de 1940. Quizá por ser potosino nos hicimos amigos. Resulta que tengo la gran fortuna de contar con grandes y simbólicos amigos potosinos. Simbólicos pues representan quiebres en el curso de mi vida adulta.

No sé si puedo decir que mi intervención se podría entender como "Tres anécdotas en torno a un amigo: Crescencio y el Colmex". Esto suena casi como un título clásico del Maestro. Para mí es inconcebible el CEDUA y desde luego el Colmex sin la figura y la presencia del Maestro. Él sabía la historia del Centro, conocía el presente y creo que hasta el futuro... De esta última fase ya no tuve la oportunidad de hablar con él, pues los últimos años estuvo enojado o sentido conmigo. ¿Por qué? La respuesta ya no es posible, ya no hubo "último encuentro" como en la novela de Sandor Marai.

Voy a platicarles la primera anécdota: de regreso a la Ciudad de México de una reunión (la primera) que se organizó creo que en 1977 en Monterrey sobre migración internacional, a la que me invitó Luis Unikel aun antes de que entrará yo al Colmex, subí al autobús que nos llevaría al aeropuerto y noté que todos los asientos se encontraban vacíos salvo uno en medio con un pasajero sentado junto a la ventana. Subrayo en medio pues significa mucho pero resulta complicado explicar. Mi oportunidad, pensé, y él se sorprendió de que habiendo todos los lugares adelante y atrás para escoger, me sentara con él para iniciar con la frase: "Eres el mismísimo Crescencio Ruiz Chiapetto". Nuestra amistad, por su culpa, sólo duró 30 años.

Estudió Derecho en la Universidad Autónoma de San Luis Potosí. Su tesis "Principios teóricos para una explicación de nuestra estabilidad política" -así mero la tituló-, mostró ya su forma cautelosa y sólida de abordar el conocimiento y sus temas de interés. El doctor Ruiz Chiapetto, su hermano mayor, me dijo que mientras él tomaba un curso de letras clásicas en un centro de Humanidades que se abrió en la UASLP en esa época, Crescencio se metió a un curso de filosofía. De allí se fue a la capital; salió para no volver. Nosotros -decía- íbamos al DF pero nos hospedábamos aún en temporadas largas en hotel. Él llego a la Ciudad de México y consiguió casa. ¡Aquí quiso y aquí vivió! Creo que casi se puede decir que vivió en el Colmex desde siempre: cuarenta años, ipoca cosa! Empezó como alumno de la maestría en Economía 
en 1967, aunque un tiempo estuvo en la Universidad de Pittsburg, en 1971, donde cursó una especialización y obtuvo el grado de maestro en Urban and Regional Planning.

No se como leer el currículum vitae de Crescencio que Estela Esquivel me juntó ahí más o menos con algunos faltantes y varias redundancias. Estoy seguro que Estela está mejor preparada que yo para reportar minuciosamente la producción académica de Crescencio, pues ella y el señor Macías lo acompañaron y asistieron en todo su trabajo y más. Menos podría saber leer su vida académica. Sin embargo, quisiera dividirla en varias etapas. Una primera hasta más o menos principio de los ochenta, que no sé si él aceptaría pudiera dividirse en antes y después de conocernos (suena pretencioso de mi parte pero desearía que así fuera). La segunda quizá hasta 2000, y la última la más reciente.

La primera está dedicada a problemas relacionados con el sector agrícola y la migración. Leí esos primeros trabajos de los setenta antes de conocerlo, cuando revisé las revistas que había sobre temas regionales y urbanos en la sección latinoamericana en la biblioteca de la LSE. De estos trabajos se acordarán bien Susana Lerner, Rodolfo Corona, los Zazueta, Jorge Bustamante, y creo que también Pepe Morelos, colegas todos con quienes debe haber cruzado disciplinas e intercambiado sabiduría.

Hay trabajos sobre migración a principios de los ochenta y una "Revisión tridimensional del fenómeno migratorio en México". Un "Panorama de las teorías de la migración en los años setenta" y uno más reciente "Migración interna y desarrollo económico: tres etapas", publicado en 1991 en Estudios Demográficos y Urbanos.

No sé cuántos artículos publicó en nuestra revista, pero hace poco me decía Carlos Garrocho que uno de Crescencio en Economía, Territorio y Sociedad, de El Colegio Mexiquense, es el más leído de los que están accesibles en línea. No dudo que lo mismo pasa con algunos de los que publicó en Demografía y Economía y en Estudios Demográficos y Urbanos.

Por supuesto el tema migratorio permea la segunda etapa de su análisis del desarrollo urbano a partir de los ochenta. No es gratuito que le haya gustado tanto el artículo de Mannie Geyer y Kontuly de 1993 sobre "urbanización diferenciada" que constituye algo así como la síntesis de los procesos de distribución del crecimiento urbano en los sistemas de ciudades en todas partes del mundo, a partir de la idea de Zelinsky de la transición en la movilidad de la población. Este tema llamó la atención del Maestro y permitió la publicación de algunos textos que seguramente ya son clásicos. 
Por ahí en los ochenta juntos elaboramos una propuesta de investigación para estudiar las ciudades de la frontera norte que en esos años eran ciudades medias (ahora Tijuana y Ciudad Juárez ya son millonarias). Presentamos el proyecto en una de esas reuniones que el entonces presidente de El Colegio de México, el señor Urquidi, convocaba anualmente. Por supuesto, su reacción fue feroz y tajante: "Todo lo que tiene que ver con la frontera lo estudiará el recién abierto Colegio de la Frontera Norte”. “¿Qué hacemos?", le pregunté a Crescencio. "¡Pues estudiemos todas y allí incluimos a las de la frontera!”, fue su respuesta. Esto quizá no suene muy teórico ni muy epistemológico, pero allí surgió el interés que hemos compartido por el sistema de ciudades y las ciudades medias.

La segunda anécdota tiene que ver con esta segunda etapa: en una reunión estábamos Crescencio Ruiz Chiapetto y yo sentados junto a una ilustre y aguerrida colega que nos cuestionó: "Eso que estos investigadores del Colmex estudian no existe”. Así que Crescencio pidió la palabra y le dijo: "Mira, las ciudades medias son aquellas que quedan entre las grandes y las pequeña”. Ahí acabó la profunda reflexión epistemológica que había intentado esa colega.

A fines de los ochenta decidí irme un rato a El Colegio Mexiquense, por invitación de Omar Martínez Legorreta y a sugerencia del señor Urquidi. Aquí surge la tercera anécdota: fui a ver a Mario Ojeda, entonces presidente del Colmex, para decirle que me iba un ratito de El Colegio y me dijo: "Bueno, creo que te vas al Mexiquense porque no nombré a tu cuate director del Centro". Le dije que no, que tenía otras razones, y me dijo que pensaba que yo prefería ser "cabeza de ratón" en vez de "cola de león”. Siguiendo con la metáfora le expresé que esperaba no tener que regresar del Mexiquense con la "cola entre las patas". Los dos años que estuve allí interrumpieron casi cinco de generosa e inolvidable convivencia que Crescencio, Martha Elena y Mariana me brindaron diariamente al mediodía en su casa. Con ellos comí exquisito y conversé mejor que eso.

A partir de 1990 y creo que durante toda esa década Crescencio Ruiz Chiapetto escribió sobre aspectos analíticos relacionados con la modernización de las ciudades, México como país urbano, las ciudades del siglo Xx y ya más reciente, a fines de los noventa, la preocupación era el desarrollo económico y el siglo XXI: "Población y migraciones rurales en México: hipótesis para otro siglo” publicado en 1999 en la revista del Mexiquense, y sobre desarrollo regional un capítulo de libro en inglés (1996) y un artículo en Comercio Exterior (1999), dos trabajos 
que firmamos juntos - de los que me siento orgulloso- pues al fin el Maestro aceptó publicar conmigo. Desde luego participamos a lo largo del tiempo en muchos proyectos y colaboraciones financiados por dependencias de gobierno, sobre desarrollo urbano, sistema de ciudades y reestructuración regional en México.

Quiero destacar, finalmente, un capítulo de libro que me tocó revisar que refleja a la perfección y de manera nítida el trabajo académico de Crescencio: "La regla rango-tamaño y las ciudades intermedias: una nota con diez gráficas". Lo menciono pues es reciente (2005) y representa desde mi punto de vista la combinación fina y elegante que él siempre cultivó en sus escritos: por una parte, la capacidad analítica para manejar sin lagunas de entendimiento los aspectos formales de un argumento; y por otra, la revisión amplia y profunda de los textos básicos sobre el tema para no dejar huecos en la línea de pensamiento que se proponía seguir.

En fin, decía el Maestro que dado que producía poco, muy poco podían también criticarlo. Creo que la crítica que pudiera hacerse a Crescencio Ruiz Chiapetto es precisamente que no produjo más.

Breves notas sobre la actividad desarrollada por el profesor investigador Crescencio Ruiz Chiapetto

\section{José Macías}

Fue en 1973 que se me presentó la oportunidad de integrarme a El Colegio de México, y concretamente al entonces denominado Centro de Estudios Económicos y Demográficos (CEED). En ese año una de las principales actividades del Centro, si no es que la principal, era continuar con la elaboración del libro El desarrollo urbano de México. Diagnóstico e implicaciones futuras. Este libro fue coordinado por el ingeniero Luis Unikel Spector, con la colaboración de los profesores investigadores Crescencio Ruiz Chiapetto y Gustavo Garza Villarreal. Hasta la fecha este libro tiene mucha relevancia como guía de los métodos para la investigación del tema.

El profesor investigador Ruiz Chiapetto contaba con licenciatura en Derecho, posgrados en Economía y en Urbanismo. Tenía a su cargo la elaboración de los capítulos: VI. "Desarrollo económico regional y urbanismo" y VII. "Factores determinantes de la migración rural urbana”. 
A mi ingreso al Centro, el entonces director, licenciado Gustavo Cabrera, me asignó a colaborar con el profesor Ruiz Chiapetto, quien por sus conocimientos y actividades era muy riguroso en sus juicios y visión tanto para la investigación como en la calificación de los resultados, por lo que para mí, más que un jefe fue un Maestro.

Desde aquel 1973 y hasta su desaparición permanente, siempre me distinguió para colaborar en sus múltiples proyectos que se veían realizados en conferencias, revistas y libros de su especialidad, investigaciones a escala nacional, estatal o municipal, sobre comportamientos de la población, integración de zonas metropolitanas y causas y efectos de la migración. También determinación del desarrollo económico en el ámbito municipal o estatal con base en los sectores, subsectores y ramas de la industria de transformación y los de servicios.

Algunas de sus últimas publicaciones son: "Proceso productivo, crecimiento y distribución de población en la zona de influencias del ingenio Emiliano Zapata"; "Desigualdades regionales en México, 19901993. La regla rango-tamaño y las ciudades intermedias, una nota con diez gráficas", y "Distribución de la población de México en el siglo xx, lectura de un artículo" (edición en español y en inglés).

Sería muy extenso enunciar la gran cantidad de trabajos de diversos temas que realizó a lo largo de su trayectoria por El Colegio. Todos ellos los abordó con alto desarrollo profesional, y compartió siempre sus avances y resultados con sus colegas. Su actuación fue ampliamente reconocida por prestigiadas instituciones del país.

La labor del profesor investigador Crescencio Ruiz Chiapetto fue muy creativa y de gran utilidad para generaciones actuales y futuras de estudiantes de la demografía y el urbanismo. Además, por su actuación siempre sencilla y honesta, su conversación agradable e interesante en ocasiones con algún detalle festivo, obtenía la amistad, respeto y aprecio de sus compañeros y personas que lo conocieran, por lo que estoy seguro que siempre será recordado de forma muy especial y afectiva.

\section{Palabras sobre Crescencio Ruiz Chiapetto}

\section{Carlos Garrocho}

Me invitaron a que dijera algunas palabras sobre nuestro amigo Crescencio en su faceta de profesor. Sin embargo pienso que a él no le hubiera gustado que en una ocasión como ésta me acartonara y me 
restringiera a hablar de migraciones, del desarrollo urbano de México o de la extraña fascinación que me inculcó por las lecturas y las referencias clásicas. De eso y de otras cosas simplemente diré que Crescencio me enseñó mucho más de lo que le pude aprender.

Así que he decidido ir más allá y hablar de Crescencio no como profesor, sino como lo que fue para mí: un Maestro. Trataré de ilustrarlo con algunas viñetas breves, que espero perfilen su recuerdo, $m i$ recuerdo, a grandes trazos. Así que, como le hubiera gustado a Crescencio, enemigo de las falsas formalidades y los protocolos innecesarios, y gran aficionado al béisbol, para empezar mi intervención simplemente diré: ¡Playbol!

Efectivamente, Crescencio disfrutaba enormemente el béisbol, especialmente la serie mundial, y tenía grandes conocimientos sobre el llamado rey de los deportes. Pocos como Crescencio para jugar "con el librito" (ustedes me entienden). Recuerdo aquella frase del Mago Septién que tanto disfrutamos Crescencio y yo una mañana aquí en la sala de profesores del Colmex: "En el béisbol ['como en el rollo urbano', añadió Crescencio], los promedios son profetas que miran al pasado".

Si hubiera sido pitcher, Crescencio no hubiera podido, ni querido, ser lanzador de poder, de esos que tiran rectas de casi 100 millas por hora. No, él habría sido lo que fue, un lanzador fino, y más que fino, sutil. Suicida del control, artista del riesgo. Despreciaba la fuerza y valoraba el talento. Puesto a escoger, prefería la estafa artística al asalto a mano armada. Así que él hubiera sido un lanzador de curvas impredecibles como serpentinas, de sliders tan delicados y letales que dejarían a sus adversarios, como nos consta que ocurría en la vida real, sorprendidos, sin palabras, con el bat al hombro. Ojo, Crescencio sabía que a menudo la distancia más corta entre dos puntos es la curva.

Había que tener cuidado con Crescencio. Era discriminatorio. En alguna ocasión me confesó: "Si hay algo que no soporto es a los pendejos". Me hice el disimulado. "Pero lo peor [continuó] es que les tengo miedo”. “¿Por qué?”, le pregunté, y mirándome con su inmensa sonrisa de duende travieso me contestó: “PPorque son un chingo!”.

Crescencio tenía una rara habilidad para generar frases certeras, concisas, lapidarias. En aquellos tiempos en los que incursioné en el sector público, me tocó organizar un gran evento para explorar el futuro de San Luis Potosí. El gobernador me había autorizado la reunión, pero tenía que ser "grande”. Así que contraté el salón más grande del hotel más caro de la ciudad y mandé hacer una gran man- 
ta ahulada para el presidium. Tenía que ser la más grande jamás exhibida en San Luis. Más de 30 metros de largo por seis de ancho. No hubo manera de confeccionarla en San Luis, así que la mandamos a hacer a México. Cuando la colocaron la vi más que monstruosa, hitleriana. Me preocupé. Pero me quise convencer de que era sólo una percepción producto de mi angustia. El día del inicio del evento, minutos antes de la inauguración, entré con Crescencio al gran salón, abarrotado de asistentes (entre genuinos y acarreados), donde estaba el gran presidium (y la gran manta). Crescencio percibió el ambiente, observó la manta y sonrió socarronamente. Luego me pasó un brazo sobre el hombro y sin saberlo demolió mis últimas reservas de confianza, cuando me dijo agitando divertido su melena gris: "Maestro, esto es dantesco".

Crescencio podía ser también preciso y demoledor con sus acciones. En otra ocasión, hará cosa de quince años, aquí también en el Colmex, vine a hacer no sé qué trámite. Me acompañaba mi hijo Carlos, entonces de dos o tres años. Me encontré a Crescencio y nos pusimos a platicar. Mi hijo, impaciente, comenzó a dar lata. Le llamé la atención. Algo vio Crescencio que no le gustó. A los pocos días me llegó a El Colegio Mexiquense un sobre de Crescencio. Lo abrí, no había ni una nota. Sólo un libro: Carta al Padre, de Kafka. Les dije que era demoledor.

Crescencio, lector voraz, uno de los máximos conocedores de los laberintos de la biblioteca del Colmex (y del Colmex mismo), me hacía el raro favor de leer mis borradores y de regalarme invaluables consejos para salvarlos del dictamen negativo. Me encantaba, cuando me iba a aclarar el panorama, aquella frase con la que iniciaba a menudo su asesoría y con la que se iba a hacer la luz, decía mirándome con sus ojos taciturnos: "Maestro, acabo de leer un articulito..."

En fin... El dolor de su ausencia está escondido en cada recuerdo que cuento. Así que mejor termino mi intervención antes de que empiecen los silbidos "del respetable". Y no encuentro mejor manera de terminar que con una frase que le aprendí a Crescencio, y que él decía haberla aprendido de TinTán (recuerden su atracción por los clásicos): "Amplias, extensas, múltiples y variadas gracias". 


\section{Crescencio Ruiz: colega y amigo}

\section{Maria Eugenia Negrete}

Los organizadores de este homenaje póstumo me han hecho una deferencia que agradezco, reservándome una participación especial: Crescencio fue en efecto mi colega y sobre todo mi amigo, y esto último es sin duda el más alto honor al que pueda aspirar cualquier persona, el tener un amigo como Crescencio. Sé que varios de los aquí presentes lo fueron también.

Después de un periodo de dos años en que el profesor Ruiz Chiapetto fue mi profesor durante la maestría en Desarrollo Urbano, y director de mi tesis, cuando entré a trabajar en el CEDDU tuve la oportunidad de transitar con él de una relación de maestro-alumna a otra como colega, compartiendo tareas de docencia, investigación y discusión de los problemas, los retos y las oportunidades que se iban presentando en el centro mismo, así como en El Colegio de México.

Le interesaba todo lo que a la marcha de El Colegio y de los centros concernía. Conocía bien las condiciones y los problemas a que se enfrentaban profesores, alumnos y administrativos; su genuino interés en el sano desarrollo de la institución lo tuvo siempre ocupado en reflexiones, discusiones y acciones en ese sentido. Impartió clases en las áreas de desarrollo urbano y demografía, dirigió tesis, participó en la junta de profesores, y en particular es destacable su paso por el sindicato de profesores investigadores, como protesorero entre 1981 y 1983 , como tesorero de 1983 a 1985, y por último como secretario general del Siprincolmex durante el periodo 1993-1995.

Como colega Crescencio siempre fue respetuoso de las opiniones de los demás, pero nunca fue condescendiente. En las instancias adecuadas presentaba sus propios puntos de vista y argumentaba como buen abogado, basado en una lúcida visión de la institución y del papel que El Colegio ha desempeñado en la vida intelectual del país. Tenía un panorama claro de las formas y procedimientos que se debían seguir en las relaciones intrainstitucionales así como con otras instituciones. En este campo asesoraba siempre a quien se lo pedía.

Crescencio tuvo varias pasiones: la primera, y muy por encima de las demás, Mariana, su hermosa hija. Quienes fuimos sus amigos sabemos bien que ella estaba siempre en su mente y en su corazón iluminando su vida.

Crescencio sentía verdadera pasión por el conocimiento y por la 
verdad científica. Por sobre todas las cosas admiraba la inteligencia del ser humano. Como científico social era riguroso y a la vez creativo, claro en los temas que abordó. Su formación económica lo hizo estar siempre cerca de temas vinculados con la economía urbana y regional, y prefería el abordaje teórico metodológico al aplicado.

Reconocía el quehacer intelectual del investigador como un proceso lento, acumulativo, de reflexión y análisis. No tenía prisa en manejar los datos con gran precisión (don Pepe, que no se equivoca nunca, lo asistía en esta labor), y elaboraba tabulaciones y analizaba la información, apoyando sus hipótesis y afirmaciones en ella.

Alguien le dijo una vez: "Crescencio, cuando te mueras no van a publicar tus obras completas sino tus cuadros completos"; le hizo mucha gracia el comentario. Escribía con sencillez y elegancia, cualidad seguramente cultivada junto a Martha Elena, su mujer. Con profunda honradez intelectual y como buen investigador le divertía hurgar en la biblioteca, entre libros y documentos, para rastrear y rescatar el origen y la gestación de los conceptos clásicos y los contemporáneos, y seguir la evolución y el desarrollo de viejas y nuevas teorías de la economía espacial.

Con nada de esto era egoísta; fue siempre generoso con sus conocimientos tanto como con su experiencia que siempre compartía de muy buen talante. No perdía oportunidad para recomendar bibliografía a sus colegas y alumnos, y si le era posible nos proporcionaba fotocopias de ella. Le encantaba sacar fotocopias de excelente calidad.

Su memoria era admirable y se preciaba de ella. Sabía exactamente el título de los artículos (prefería los artículos a los libros), el autor, el número de la revista, el año y la descripción física de los volúmenes. Sólo le faltaba mandarte al estante de la biblioteca en donde se encontraba el material. Esto era extraordinario.

Solía decir: "El trabajo de investigación siempre se reconoce y se aprecia"; por ello sus trabajos, aunque no muy numerosos, fueron y seguirán siendo profusamente citados entre los estudiosos del desarrollo urbano mexicano.

Le entusiasmaba participar e impulsaba espacios para seguir estudiando y aprendiendo, como las clases de matemáticas y estadística con Manuel Ordorica, y más recientemente los seminarios del doctorado en Economía de la UNAM, con Clemente Ruiz, los cuales tanto gozaba (eran sagrados los jueves por la mañana para asistir a ellos).

Una pasión similar era la que sentía Crescencio por las personas, sabía escuchar. Conocía bien al ser humano y pronto reconocía en sus 
interlocutores las principales virtudes y debilidades. Sabía tocar las fibras sensibles de cada uno, con una palabra, un detalle, una sonrisa en el momento adecuado, y nos hacía sentir que se ocupaba y preocupaba personalmente de cada uno. Estableció así canales de comunicación entrañables con quienes le rodeábamos y sembró afectos perdurables. Habemos aquí muchos testigos.

En múltiples ocasiones no se resistía a hacer uso de esa misma habilidad (para identificar rasgos esenciales de las personas) y bromeaba con colegas y amigos, generando siempre sorpresa y risas. Entre quienes no entendían su sentido del humor (un tanto oscuro), o no estaban de ánimo en ese momento, provocaba no pocas veces molestia o enojo; en algunas ocasiones cuando fui testigo de esto, solía aconsejarle escribir un libro titulado Cómo perder amigos y crear enemistades. Él asentía y también se reía mucho.

Otra pasión de Crescencio era el béisbol. No sabría en qué lugar colocarla, pero en última instancia era una pasión que se manifestaba sólo por temporadas y que compartía con algunos iniciados con quienes le gustaba cruzar apuestas sobre qué equipo ganaría la serie mundial ese año.

Crescencio disfrutaba charlar frente a una taza de café, una cerveza o un whisky -dependiendo de la hora del día- donde hubiera buen servicio como el de don Roberto, de la sala de profesores, y sin prisa, siempre tranquilo. No le gustaba que hubiera límites de tiempo cuando compartía una buena plática.

Conocía la Ciudad de México como usuario de taxis. No le gustaba manejar, ni tenía coche. Tampoco teléfono celular que osara interrumpirlo. Tardó tiempo en acostumbrarse a revisar su correo electrónico y no gozaba del ritmo cada vez más acelerado de los tiempos recientes. No asimilaba muchos de los avances tecnológicos pero tampoco los reprobaba, simplemente no eran para él.

Tomaba café, bebía whisky, le gustaba fumar, leía despacio, caminaba lento, pensaba rápido y sentía una preocupación genuina por la gente.

Crescencio, te vamos a extrañar con tu voz baja, tus pasos sigilosos por los pasillos, con tu imprescindible cuaderno de notas bajo el brazo, tu amplia sonrisa, tu pesimismo (que no fatalismo) y tu admirable trabajo intelectual.

Gracias colega, amigo, siempre Maestro. 